\title{
Mapping \& Modelling of Supply Chain System in a Private Indonesian Hospital Using Supply Chain Operating Reference (SCOR) \& Business Process Modelling Notation (BPMN) Method
}

\author{
Aditya Herdiyan Pratama ${ }^{1 *}$, Nurmala ${ }^{2}$ \\ ${ }^{1}$ Department of Master of Management, Faculty of Economics \& Business, Universitas Indonesia \\ ${ }^{2}$ Department of Master of Management, Faculty of Economics \& Business, Universitas Indonesia \\ *Corresponding author. Email: aditherdiyan@gmail.com
}

\begin{abstract}
Hospital is one of the most unique business as it needs to balance profit making as well as 'life-saving' in terms of customer satisfaction. Therefore, efficient \& effective operational cost management is paramount in a Hospital's sustainability. One of the most influential cost-driver in a Hospital Operation is the Pharmacy or Drugs Supply Chain. However, research regarding the Drugs Supply Chain is limited, particularly in Private Hospitals in which it has to deliver profit to the stakeholder as well as comply to government policies. This thesis proposes the use of Supply Chain Operations Reference (SCOR) to model the Hospitals Supply Chain Operations as a tool to assist in the hospital managerial analysis. While SCOR is a proven and robust method of supply chain modelling, some complementary processes may exist which are not covered by the SCOR standard. Therefore, this thesis further proposes the use of Business Process Modelling Notation (BPMN) to be used as a modelling tool using the SCOR model as a basis. The research conducted finds a few processes standardized in the Indonesian Private Hospital Operations which are not yet covered by the SCOR model such as the internal supply chain within the Hospital as well as some added process events. In this sense, the research in this thesis will contribute to the establishment of a robust Pharmacy Supply Chain Operation model practiced in Hospitals.
\end{abstract}

Keywords: Hospital Supply Chain, Pharmacy supply Chain, SCOR, BPMN.

\section{INTRODUCTION}

Hospital is a unique and one of the less opted investment opportunities. This is in part due to the fact that not every hospital operates as a for-profit institution. However, hospitals may present themselves as a potential business venture, especially in Privately owned Hospitals. One of the main barriers of hospital investment lies in the low profit margin in for-profit hospitals. Studies done in the US Health System analysis shows declining margin in the hospital business [1]. There are two basic methods of increasing a business profitability \& margin. One way is to increase sales by generating more revenue, the second is by cutting down on cost \& expense.

Research in issue of supply chain in Public hospital conducted in Italy [2] shows how the most common issue of supply chain at hand is Infrastructures, Human Resources, IT \& Staffs. Whereas, another similar research conducted in Australia shows the main issue is lack of coordination between suppliers \& hospitals [3]. However, the management \& operational challenges of Public \& Private Hospitals differ greatly, as such among different countries of said hospitals. In Indonesia, Public Hospitals are those run by governments be it local government, provincial government, or government-controlled body. 63,5\% of 2813 hospitals in Indonesia is privately owned, which generally means they are for-profit hospitals [4]. This creates a novel \& unseen investment opportunity in Indonesia.

The Private Hospital studied in this research is part of one of the biggest Hospital Chain in Indonesia, with branches across the Nation and the Hospital branch in research are certified by Indonesian Hospital Accreditation Committee or Komite Akreditasi Rumah Sakit (KARS) and Joint Commision International (JCI) both of which detailing certain standards of Supply Chain Operations, particularly for pharmacies or drugs.

This hospital, like any other private hospital in Indonesia faces challenges to generate more profit for the investors. One aspect of operational management able to directly impact a business profitability is by assessing \& leaning its supply chain expenses. In a hospital, supply chain expenses make up the second largest expense incurred after labour expenses and have been rising faster than labour expenses 
has in the past several years [5]. A detailed study conducted estimates an average of $30 \%$ of a Hospital's expense is spent on Supply Chain [6]. These facts create the urgency for Hospitals to improve the supply chain processes in order to minimize cost and maximize profit.

In order to correctly and efficiently leans a firm supply chain, one must first understand specific aspects related to the business supply chain, be it the product or the information flow. In this instance, the method of Supply Chain Operational Reference (SCOR) may provide some basic supply chain assessment framework. SCOR is a management model tool used to assess, improve, and translate business strategy into supply chain strategy developed by the Supply Chain Council, now known as Association for Supply Chain Management (ASCM). Previous research in supply chain risk management has been conducted using SCOR model and resulted in a promising framework for risk management [7]. This research proposes to make use of SCOR model as a basis framework of assessing supply chain system in Awal Bros Hospital while Business Process Modelling Notation (BPMN) will be used to portray the processes not detailed in the SCOR model. Part 2 explains the relevant literature used in this research. Part 3 shows the detailed methodology to conduct the research. Part 4 revealed the result and followed by discussion. Part 5 conclude the research with future openings on practical and theoretical development.

\section{LITERATURE REVIEW}

A research done in field of Healthcare Supply Chain states that an efficient healthcare service supply chain depends on the practice of contemporary management to ensure each element in said supply chain is effectively coordinated as well as gives added value to the supply chain [8].

Within Supply Chain Management, 2 main components exist. Organization Network Integration, and material, information \& cashflow coordination. Good supply chain partner appointment will help develop inter-organization collaboration and development of new integration concept with related partner will help achieve strategic objectives of organizations. Flow coordination along the supply chain can be realized using the latest information technology, process orientation to align supply chain activity, and using advanced planning system for planning [9].

According to a quantitative research done by in a private Jordanian hospital, it was concluded how there are significant relations between Supply Chain Management (Relations with supplier, as well as specification \& standard of logistics aftersales) with healthcare qualities given [10]. This study also increases the importance of supply chain management in service industry and its effect on service quality.

The SCOR-model has been created to portray the business exercises related to all aspects of fulfilling a client's interest. The model itself contains a few areas and is categorized to six essential administration procedures of Plan, Source, Make, Deliver, and Return [11]. By portraying detailed supply chains model utilizing these process building blocks, the model can be utilized to depict flexibly chains that are straightforward or complex utilizing a typical arrangement of definitions. Thus, separate businesses can be linked to portray the profundity and broadness of any supply chain.

Documentation by $M$. Dumas et al. presented a definition of Business Process Management (BPM) as the art and science of overseeing how work is performed in an organization to ensure consistent outcomes and to take advantage of improvement opportunities [12]. Other research states how Business Process Modelling is relevant with healthcare service industry when correctly planned, implemented, executed, integrated using management approach as well as continuous improvement the business process so as to be in line with the organization strategic directives [13]. BPM is made up of 6 elements, which are: Strategic Alignment, Governance, Methods, Information Technology, People \& Culture. Usage of BPM becomes important to ensure organization competitiveness through its improvement of business processes.

\section{RESEARCH METHODOLOGY}

Based on the literature review from SCOR documentation, the systematic literature review and early hypothesis, the supply chain system of the Hospital was modelled using SCOR format. Based on previous research a modelling of Supply Chain using SCOR processes reference, the model can be split into 3 level, according to the Process Types, Process Categories, and its Process Elements [14].

In this step, the modelling is done according to the first, second, and third level of SCOR. According to SCOR release 11 documentation, level 1 describes the overall scope and content of the supply chain, while the level 2 defines the supply chain operations strategy. This step will model the overall operations of the Hospital Supply chain, specifically the Pharmacy Unit which deals with Drugs supply chain within the hospital. The level 3 itself will detail every process involved within the hospital as well as its supporting process elements.

The next step to be done was to model the third level of SCOR, however in order to correctly and accurately model each process elements Input \& Output information as a SCOR model demanded, a deeper understanding of the inner-working of the hospital supply chain is needed, so based on the basis of the SCOR Level 2 model, and the SCOR level 3 framework, an in-depth interview was conducted to the hospital management.

The interview discussed every aspect of the hospital supply chain operations and management, and by the end of it the information required to create the SCOR model was 
acquired. In the Hospital, the management hierarchy is split into 3 level which are the Upper Management, The Middle Management as well as the Lower Management. In order to completely cover all level of Management, the In-Depth Interview has been conducted towards the Hospital Director, Medical Manager, and Pharmacy Unit Coordinator of the Hospital. The Interview was done in a one-by-one manner rather than a group discussion so as to avoid an opinion bias due to the difference in positions of the Respondents, one being the superior of another.

The third level of SCOR describes the Process Elements of each Process Category. For example, a single Process Category of Source Stocked Product (sS1) involves 5 process elements, which are Schedule Product Deliveries (sS1.1), Receive Product (sS1.2), Verify Product (sS1.3), Transfer Product (sS1.4), and Authorize Supplier Payment (sS1.5), this shows the extent to which the SCOR level 3 details each activity. In addition, each process element also requires some input $\&$ output process, which differs from each industries and institution depending on their policy and Standard of Procedure. This is the reason why the in-depth interview was necessary before completing the SCOR level 3 model.

Next to further details the SCOR modelling, the BPMN modelling was conducted which serves as an alternative to the SCOR level 3 model as it details each process in the Supply Chain Operations. Some research shows how the BPMN may also serves as the Level 4 modelling, as it may detail more information than the standardized SCOR [15]. The BPMN modelling will be done using BPMN template and details each process category specified in the SCOR Model. The BPMN Modelling will be done in accordance to Dumas literature [12].

\section{ANALYSIS AND DISCUSSION}

At the level 1 SCOR model, a hospital makes a strategic decision. In this case, a hospital must define what activity goes on at the hospital supply chain, specifically the Drugs supply chain. At its core SCOR process is split into 6 main processes in the first level, Plan, Source, Make, Deliver, Return, and Enable. Every supply chain involves an Enable process, however within a SCOR model, it doesn't include the Enable Process, this fact is based on several journal which has modelled a supply chain within a company using SCOR [14] [15] [16] [17] [18]. Using this assumption, only 4 Process types are applicable in a hospital's Drugs supply chain environment due to the fact that no production of Drugs is done in the hospital environment. The 4 applicable processes are Plan, Source, Deliver, and Return.

Strategically, the supply chain activity within the hospital spans the Hospital P Process describing overall planning for the hospital supply chain, Hospital S Process describing the Drugs sourcing from the supplier, Hospital D Process describing drug delivery to customers (patients), and Hospital $\mathrm{R}$ Process describing return activity for defective or expired (excess) Drugs.

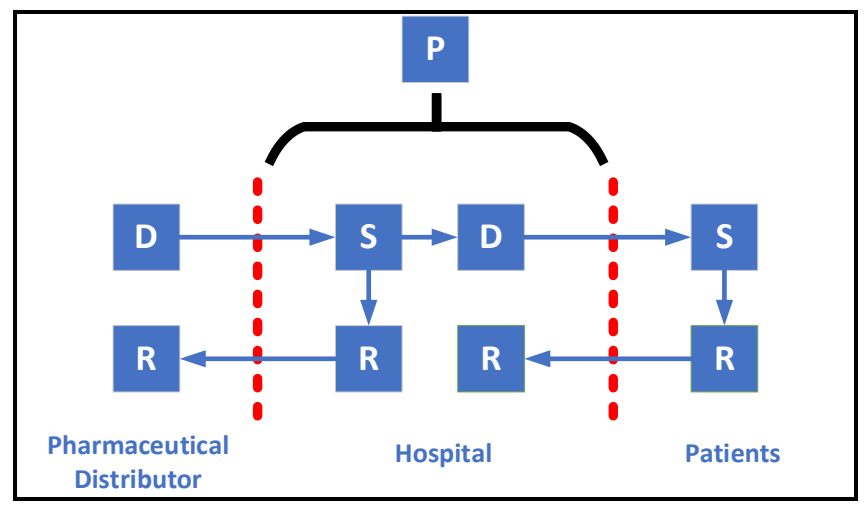

Figure 1 The Level 1 SCOR Model

The Respondents to give revision for the Level 1 SCOR model was the Hospital Director \& The Pharmacy Unit Coordinator by confirming there is indeed a Return Process occurring from the Patients to the Hospital in special cases, therefore the Final Level 1 SCOR model for the Hospital is given in Figure 1.

The second Supply Chain Process Modelling to be done is the SCOR Level 2 Model. In this level, each process given in the previous Level 1 SCOR model was further detailed. In this level the category of process being done in the previous level was further seen, for example a Sourcing Activity (S), may describe Sourcing activity which is done for stocked item, or made-by-order item. In this case, each Process Type in the Level 1 which are Plan, Source, Deliver $\&$ Return each has their own categories.

The processes started with the planning, specifically with the process sP1 which is the Supply Chain Planning. In this phase the processes associated with determining the requirement to achieving the objective for the Hospital supply chain is laid out, so it can be further detailed in the proceeding Planning. The next planning to be done has to do with the procurement activity, which is described in $\mathrm{sP} 2$ or Sourcing Planning. In this process the hospital will develop and establish courses of action over a specified time period to create a projected estimation of Drugs required to supply to the patients. In the next process which is $\mathrm{sP} 4$ or Delivery Planning, includes the required course of action to supply the procured drug towards the customer or the patients, this may span from inventory management to pharmacy transfers. The final planning process to be done is sP5 or Return Planning. In this planning process, the hospital must plan the return process for defective drug which started during the procurement quality check, as well as the return for expired drug which in SCOR processes is dubbed as the Excess product.

After the planning, comes the execution processes which started with Sourcing process, specifically $\mathrm{sS} 1$ which is Sourcing Stocked Products. In Drugs industry, most Drugs purchase done by Hospitals are for stocked products, Sourcing of Made-by-Order Product are reserved only for the very large institutions such as Health Ministry. During 
the procurement process or the $\mathrm{sS} 1$ process the hospital orders a sum of specific required Drugs, as well as perform quality check for the received drug. The next process is drug delivery which describes the Drugs delivery to patients dubbed as sD1. In sD1 the delivery for stocked product is done, and this is done mainly by pharmacy towards purchasing patients as it does not actually involve logistics delivery, also all "delivery" made is for stocked products as a hospital does not produce its own Drugs. The next process is sSR1 which is Sourcing Return for Defective Product. This is in response of the original Sourcing process in which if during the product receival inspection a bad quality product is encountered, it will be returned to the Supplier. The other return process to be done is sSR3 which is the Sourcing Return for Excess Product. At the end of the Drugs shelf life, or the end of its expiry date, Drugs does not get thrown away, rather they get returned to the supplier, so from the viewpoint of the hospital there are no wasted products.

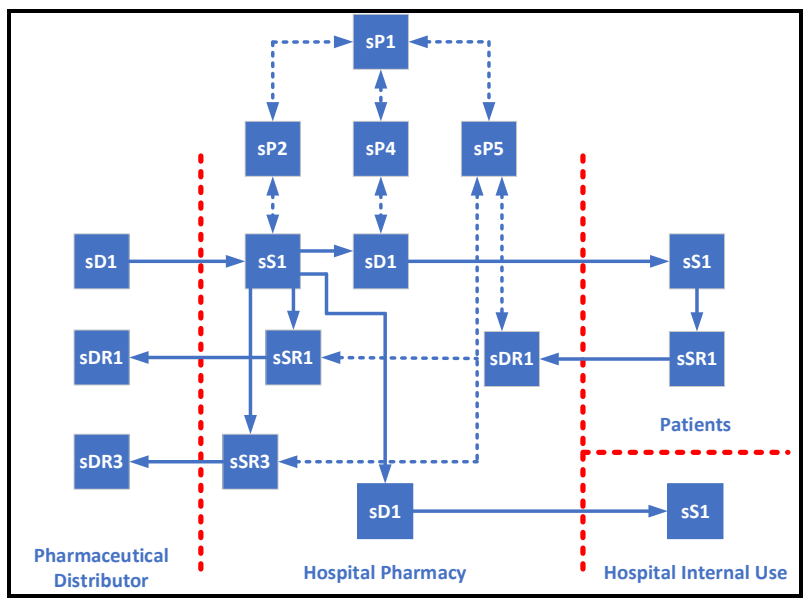

Figure 2 The Level 2 SCOR model

In the Final Level 2 SCOR Model, the Process involved in the Supply Chain Operations for the Hospital are Source Stocked Product, Deliver Stocked Product, Source Defective Product Return, Source Excess Product Return and Deliver Defective Product Return. There are two Deliver Stocked Product Process involved, the first is the Product Delivery for Patients as the 'traditional' Customer for Hospital's Pharmacy. The second is the Hospital Internal Units such as Operating Rooms and Doctors Rooms. The Deliver Defective Product Return has been added in light of the Patients Drugs Return process previously modelled in the Final Level 1 SCOR model as informed by the Interview Respondents.

To begin, the sS1 process is broken down into 5 process elements, starting from Scheduling, Receiving, Verification, Transferring to Inventory as well as authorizing payment. The Source Stocked Products Process still includes all Process Elements previously included in the early model. However, the process element Authorize Supplier Payment $\&$ Product Transfer is switched in terms of process flow, in that the Authorize Supplier Payment now comes before the Product Transfer. The Final model for $\mathrm{sS} 1$ is given in Figure 3.
The Input \& Output Item of each process Element has also been added in the Final sS1 Level 3 Model. For the Schedule Product Deliveries Element, the Input given are Sourcing Plan, which are represented by the Hospital Formularium and Defecta Tool helping the Logistic Staff to determine what Drugs to source as well as when to source them. Formularium serves as the tool which maintains the list of drugs able to be procured and used in the Hospital, while Defecta is used to maintain the Hospital Inventory. The Output, as it normally is, is Purchase Order to Supplier. The Input for Product Receive is the Product itself, while the Output for Verify Product is Receipt Verification, this ensures the Product Receipt Verification is only issued once the product is affirmed to be in good condition. The Authorize Supplier Payment Output is the Payment info, issued in the form of Invoice Clearing from the Pharmacy Logistics to the Finance. Last, the Transfer Product Output is the Transferred Product itself, ready to be distributed to the Customers, whether it is the Patients or the Internal Users.

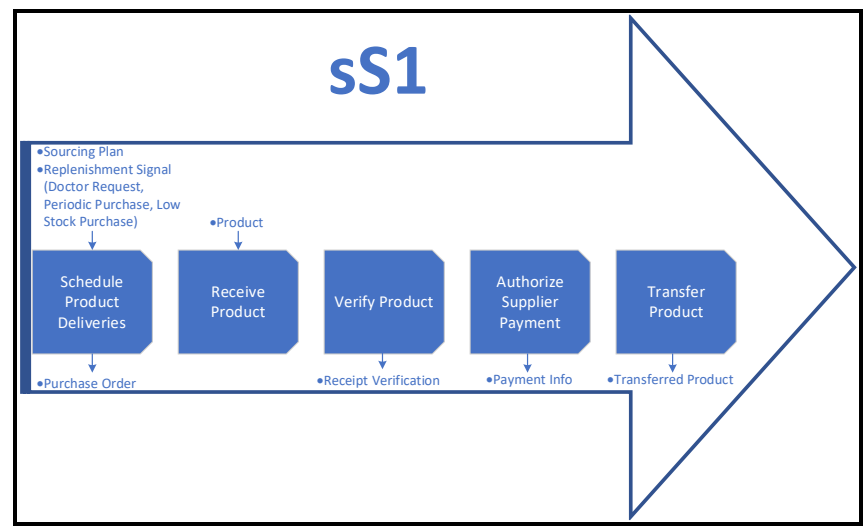

Figure 3 The Level 3 sS1 SCOR model

The sD1 process, or Deliver Stocked Product Process begin by Process Inquiry, which means receiving Drugs Prescription - written by the attending doctor - from the patients. After that, the Pharmacy will verify Drugs availability and validate whether or not the prescription paper is authentic. After verifying the order, the pharmacy will inform the storage team to fetch and prepare the Drugs to be delivered to the patients. Once receiving the Drugs from the inventory, the Drugs are given to the awaiting patients. The patients may then verify the received Drugs are as prescribed by the doctor and as ordered. The payment $\&$ invoice process are usually done just as the product is being prepared, before the Drugs are given to the customer.

There exist a few variations of Deliver Stocked Product, the first of which is Deliver Stocked Product for Conventional Patients. In this process, the product delivery for patients attending the Out-Service treatment is given, the Drugs purchase procedure usually follows after the Doctor Consultation, and the Drugs Prescription is given by the Consulting Doctor. At which point the Patient will inquire the Pharmacy Unit for the Drug Purchase. The detailed Process Elements for Deliver Stocked Product for Patients is given in Figure 4. The Process starts with Customer Inquiry, 
under the Doctor Prescription. As previously informed, the next process is Invoice with Payment from the Customer as the Output. After the Drugs are validated and assured to be in stock, the product is received from the Inventory and are given to the Patient. At which point, the Pharmacy will help the customer to ensure the Drugs given are the correct ones. The process ends with the product receive \& verification.

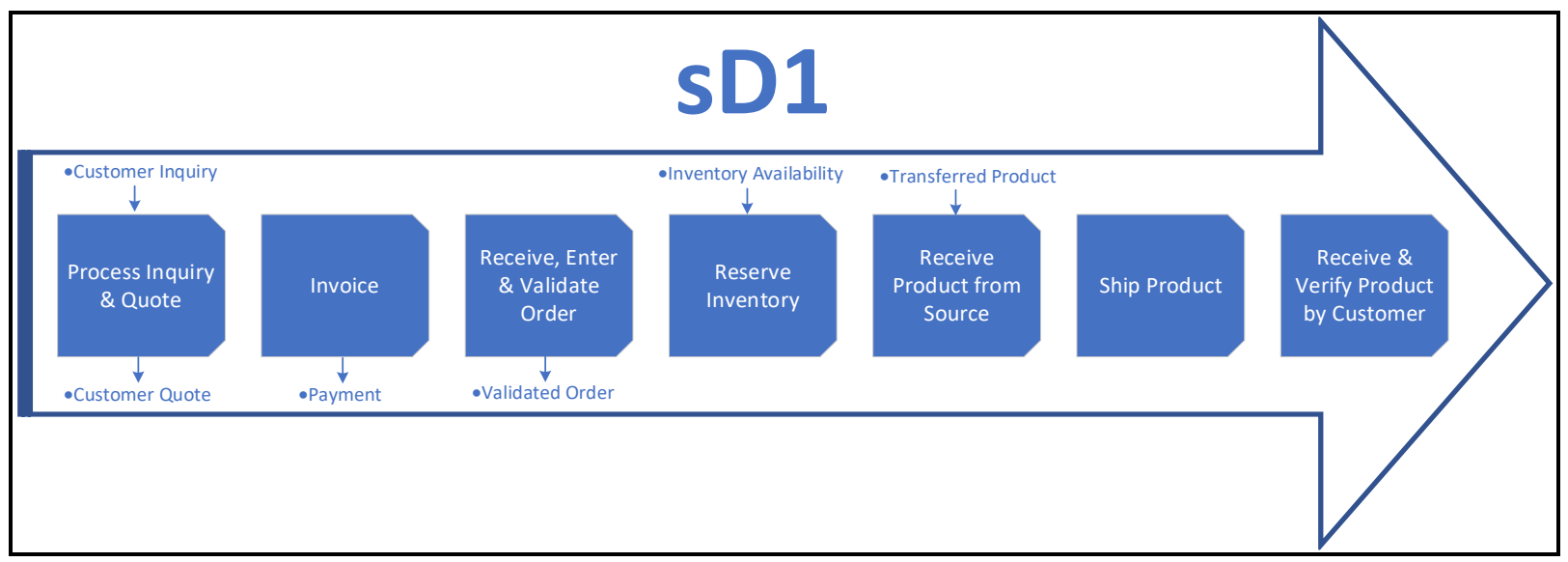

Figure 4 The Level 3 sD1 SCOR model for Conventional Patients

The Deliver Stocked Products for Telemedicine Patients are a novel addition to the SCOR model in terms of applicability, in that it involves actual product logistics \& shipping. As explained, the process begins with Telemedicine Doctor Consultations ending with the Doctor Drugs prescription. At which point the Drugs prescription goes straight to the Pharmacy Unit to be prepared for Patient
Invoicing and Product Packing. After, the Pharmacy Unit will coordinate a shipping procedure with a partnered thirdparty logistics, which is Go-Jek, giving the shipment information and ensuring the Drugs are received by the Patient. Figure 5 details the Deliver Stocked Products for Telemedicine Patients.

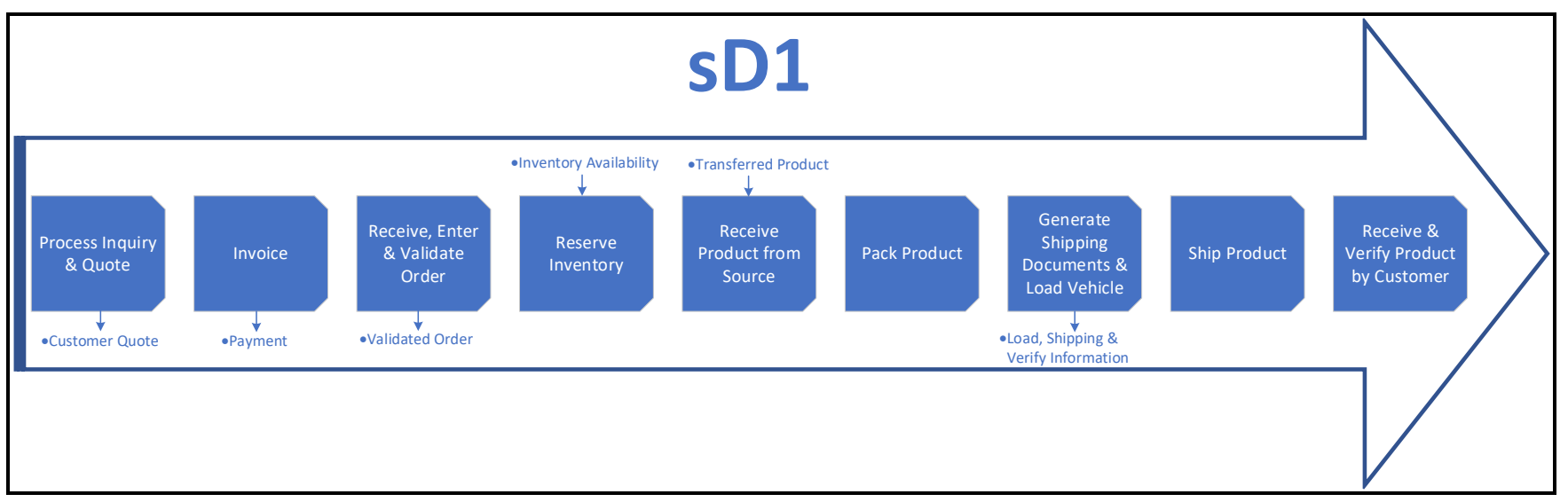

Figure 5 The Level 3 sD1 SCOR model for Telemedicine Patients

The Only difference in the Process Element of Delivery for Internal Hospital Users lies in the Invoicing Process, in which it is not charged for payment by the Pharmacy, rather the transfer of Inventory data from the Pharmacy to the requesting Units, so the Drugs are now under the Requesting Units Inventory. The Figure 6 shows the sD1 for the Internal Use Delivery Process which excludes Invoice Process Element from the original modelling. 


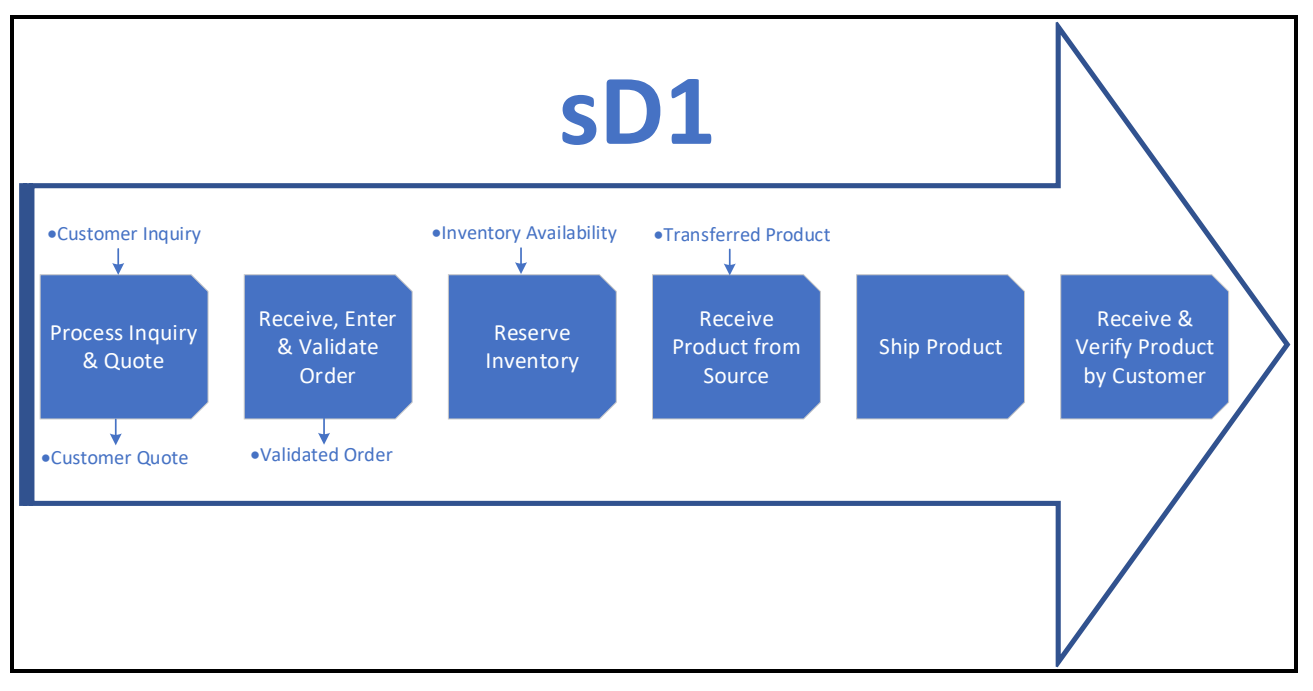

Figure 6 The Level 3 sD

The next process to be modelled is the SSR 1 which is the Source Return Defective Product. First the hospital procurement must specify and agree upon the parameter for which Drugs are not acceptable and must be returned, this is usually stated in the purchase contract as well as specified by the Standard Operating Procedure of the Hospital. Next, the hospital will perform the quality check as well as separation of defective and accepted products. After, the hospital will contact the supplier to notify them of the defective products received and request product return. After the supplier confirmed the defective products, the hospital may then schedule the defective product shipment. Shipment logistics may be done by the hospital or the supplier depending on the agreed contract. Figure 7 shows the Final sSR1 model for the Hospital.

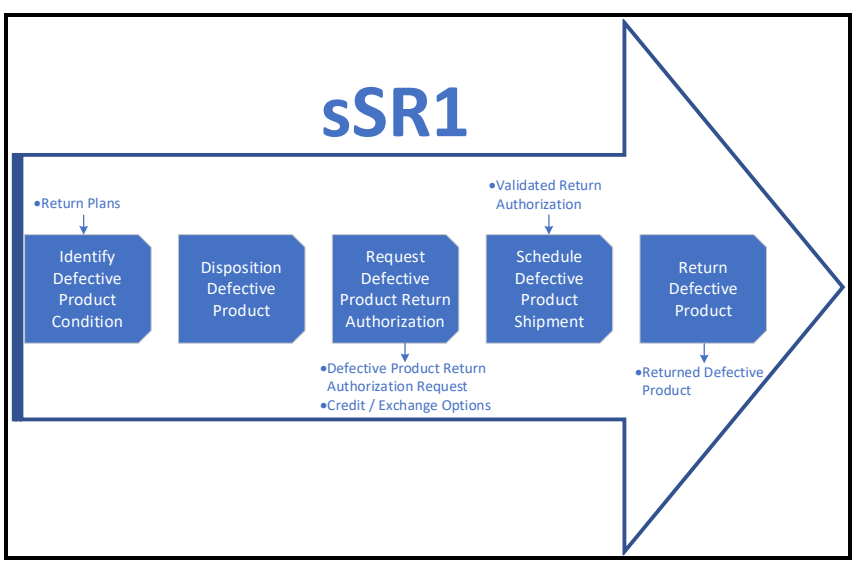

Figure 7 The Level 3 sSR1 SCOR model

The Excess Product Return refers to the return for Drugs which are not sold and are nearing or past its expiry date. The process elements involved in this process is similar to those existing in Sourcing Defective Product Return, only the products condition is changed from defect products to expired products. The first process elements which involves identifying excess product condition must be made clear during the initial contract with the supplier, as in the period for returning the product, which may be a few days, weeks or months before the specified expiry date or even until the
SCOR model for Hospital Internal User

expiry date has passed. The following process elements is similar to the Source Defective Product Return process elements.

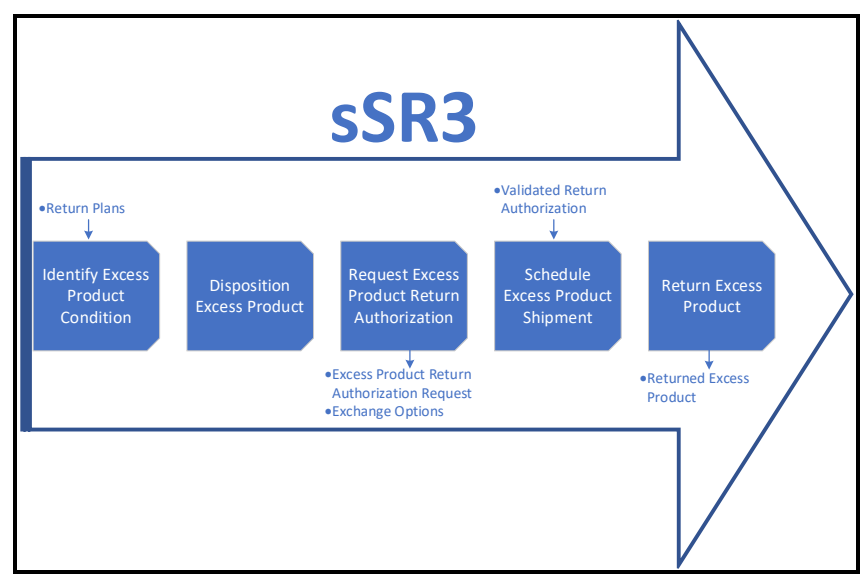

Figure 8 The Level 3 sSR3 SCOR model

The Deliver Defective Product Return is in response to the Input of the interview Respondents stating how there are certain conditions which allows for Patients Drug Return. Since in the first modelling scheme there are no initial model for the Deliver Defective Product Return, this model will be the first drawing and the final one with the added Input \& Output information embedded in the model. Figure 9 gives the Final sDR1 model for the Hospital.

The Final sDR1 model shows the whole process and the Input \& Output Information in play within each Process Elements. The first process element is Authorize defective product return, it is initiated by Patient Request and it can only be authorized if all conditions for valid return is fulfilled. At which point the Patients can return said Drugs to the pharmacy unit and transfer said product to the Inventory if the product can be re-sold or medical waste processing if the product cannot be re-sold.

Overall, the sourcing process has been covered by the SCOR level 3 Model. As an addition to the BPMN model, the Sourcing process which began by User's Inquiry is 
added. As previously noted in the In-Depth Interview part, a user request of certain Drugs does exist from time to time. However, the process requires approval from the preexisting list called Formularium. The requested Drugs must be listed in the Formularium, or when it does not, must first be approved to be included in the Formularium.

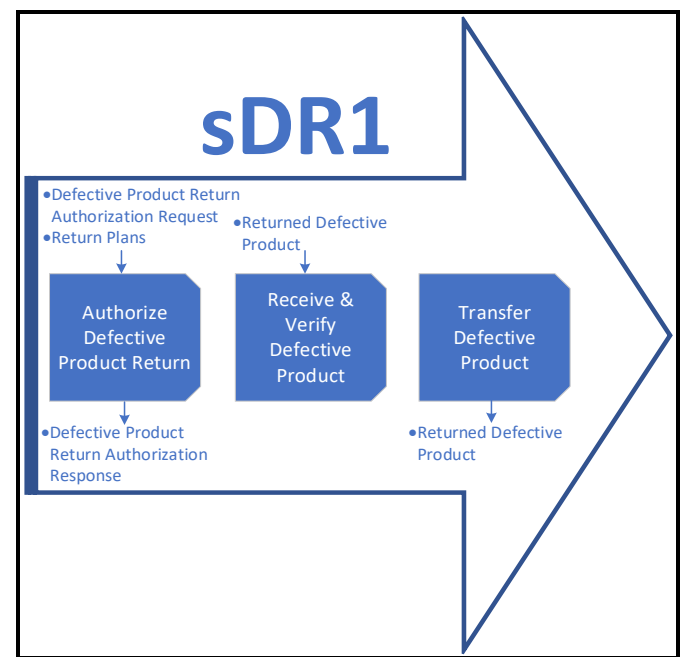

Figure 9 The Level 3 sDR1 SCOR model

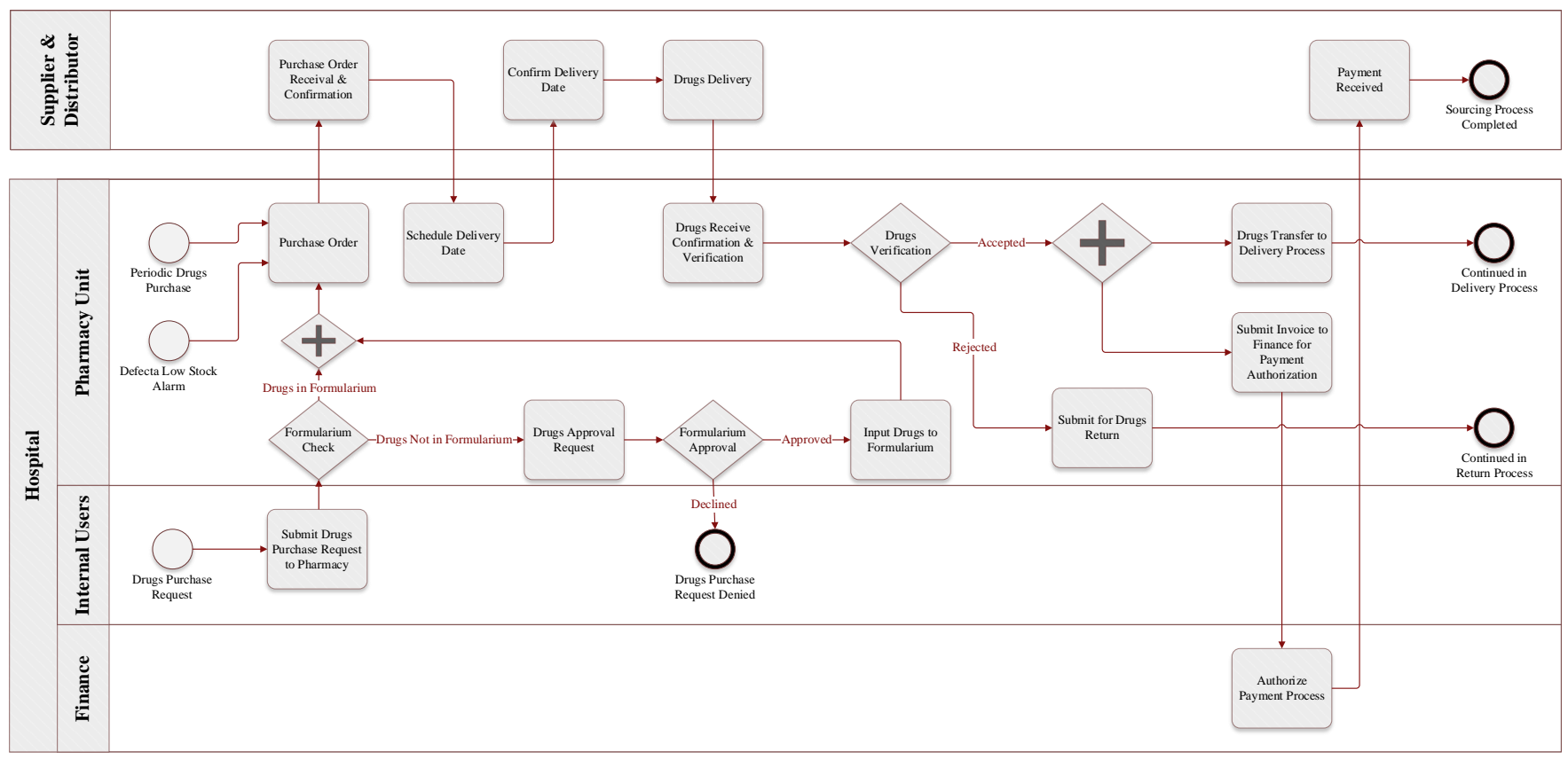

Figure 10 The Sourcing BPMN model

The first Event Process began by Periodic Drugs Purchase. As the name suggests, this purchase is done periodically for a number of types of Drugs. The list of Drugs to be purchased and the number to be ordered will be sent to the supplier via a Purchase Order. After the Principal Supplier confirms the order and appoint a distributor to deliver the requested Drugs, the Hospital will then confirm the scheduling for the Drugs logistic delivery. Once the distributor confirms the delivery date, the Drugs will be delivered at said date. At the delivery date and during the delivery process, the Pharmacy Unit of the Hospital will confirm \& verify the received Drugs, whether or not it is up to specification or whether or not a defect is present. The defect covers most scenario from physical defect to logistics defect such as Cold Chain compliance. If a Defect is identified the Drugs will be rejected and submitted for Return and the process flow ends here. If the Drugs pass the verification process, the next process done will be parallel process of Transferring the Drugs for the Delivery process $\&$ the Payment process. In the Payment process the Pharmacy will submit the drugs invoice to the Finance unit for approval of payment process. By the end of the accounting month, the Finance Unit will complete the payment process and after the payment has been confirmed by the Supplier or Distributor, the Sourcing Process is deemed to be completed.

The Purchasing or Sourcing process initiated by the Defecta is similar to the Periodic Purchase Process. The Defecta is a tool used to maintain the Minimum \& Maximum number of Drugs to be stored in the Pharmacy inventory. Therefore, the tool will raise reminder to purchase drugs when it detects low stocks in certain drug types, as well as the amount required to be purchased. In 
this instance, after the Defecta raises the reminder, of the type of drug \& the amount to be purchased, the Pharmacy Unit will create a Purchase Order, and the process goes on as the Periodic Purchase does.

The added process flow lies in the Purchase Request initiated by the Internal Users or the Doctors. In this type of purchase, the requested drugs must first be cross referenced with the Formularium list. If the requested drugs are in the existing Formularium list, the drug purchase can move forward as requested. However, if the requested drugs are not yet in the Formularium, the Pharmacy will consult the Pharmacy \& Therapy Committee which exists in every Hospital. In it the Committee will determine whether or not the requested drugs therapeutic effects are already covered by other drugs already existing in the Formularium. This is done to ensure there are less drug brands redundancies which will cost valuable storage space in the Pharmacy Unit. If the requested drugs are approved to be added into the Formularium, the Purchase moves forward with the Purchase Order process. If not, then the request is considered to be denied and the request is not fulfilled. The BPMN process presented in the model has covered most if not all of the purchasing processes which exist in the Hospital and is therefore concluded.

The Delivery Process as the SCOR model does caters to three distinct type of Users. The Internal Users, the Conventional patients, and the Telemedicine Patients. Each process shares some similarity but are ultimately requiring different process flow. Specifically, the Telemedicine patients Drug delivery due to it involving actual product shipment via third party logistic partner.

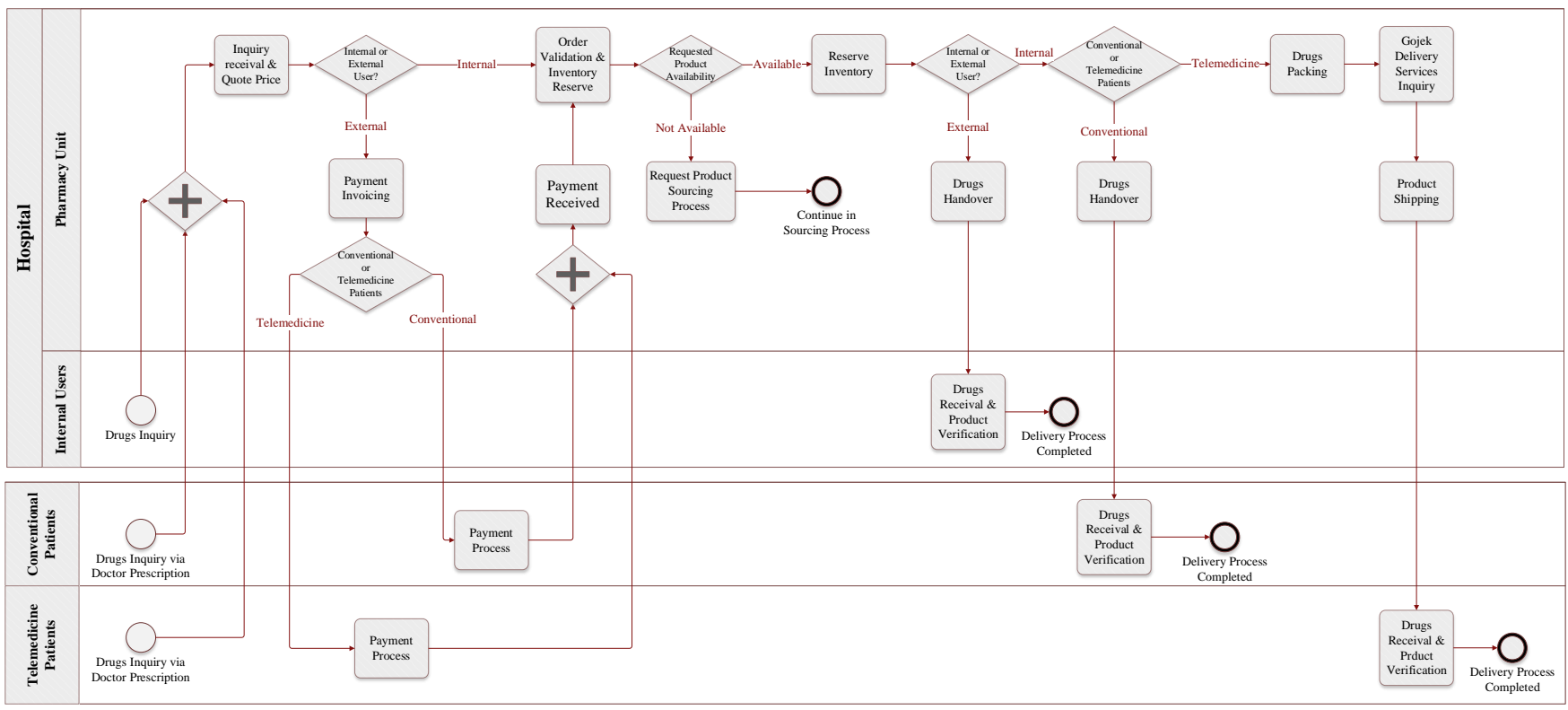

Figure 11 The Delivery BPMN model

In the Drugs request inquired by the Internal Users, the process continues with the inquiry receival and request forwarding by Pharmacy Unit to check for stock availability. If the requested drugs are not available on stock, the process of Delivery ends here to be continued in the Sourcing Process. If the Stock is available, the requested number of drugs will be reserved and processed for instant handover to the requesting Unit. The process ends here and the Inventory system of the Pharmacy Unit deems the requested drugs to be sold or used.

For the Drugs purchase by Patients, the process slightly differs for Conventional \& Telemedicine Patients. After the initial drugs inquiry, the process flow continues with the payment process by inquiring Patients. After the payment has been confirmed, the process moves on with the drugs reserve $\&$ availability check.

The second variation of process comes when the returned Drugs is not in defective condition, which means it is in the same condition as when it was received by the
Patients. At this point, the authorization must be done by the prescribing doctor in order to determine whether the return request is valid. The drugs requested to be returned must also be returned less than a month after the purchase date, if it is requested to be returned beyond the one-month mark, the request is denied and the process ends here. If the returned drugs date is within a month of purchase, the process continues with the doctor authorization. At this point, the only condition in which the drugs are allowed to be returned are when the Patient is showing allergic reaction to the prescribed drugs. If not, then the drugs return request is denied and the process ends. If the patient shows such allergic reaction, then the drugs return process may continue, where the Doctor approves the drugs return, and the Pharmacy will process the Refund process. After the patients returning the drug receives their refund, the process ends. The drug return process model is therefore concluded here, in which all scenario for drugs returns and process ending has been covered in the BPMN model. 


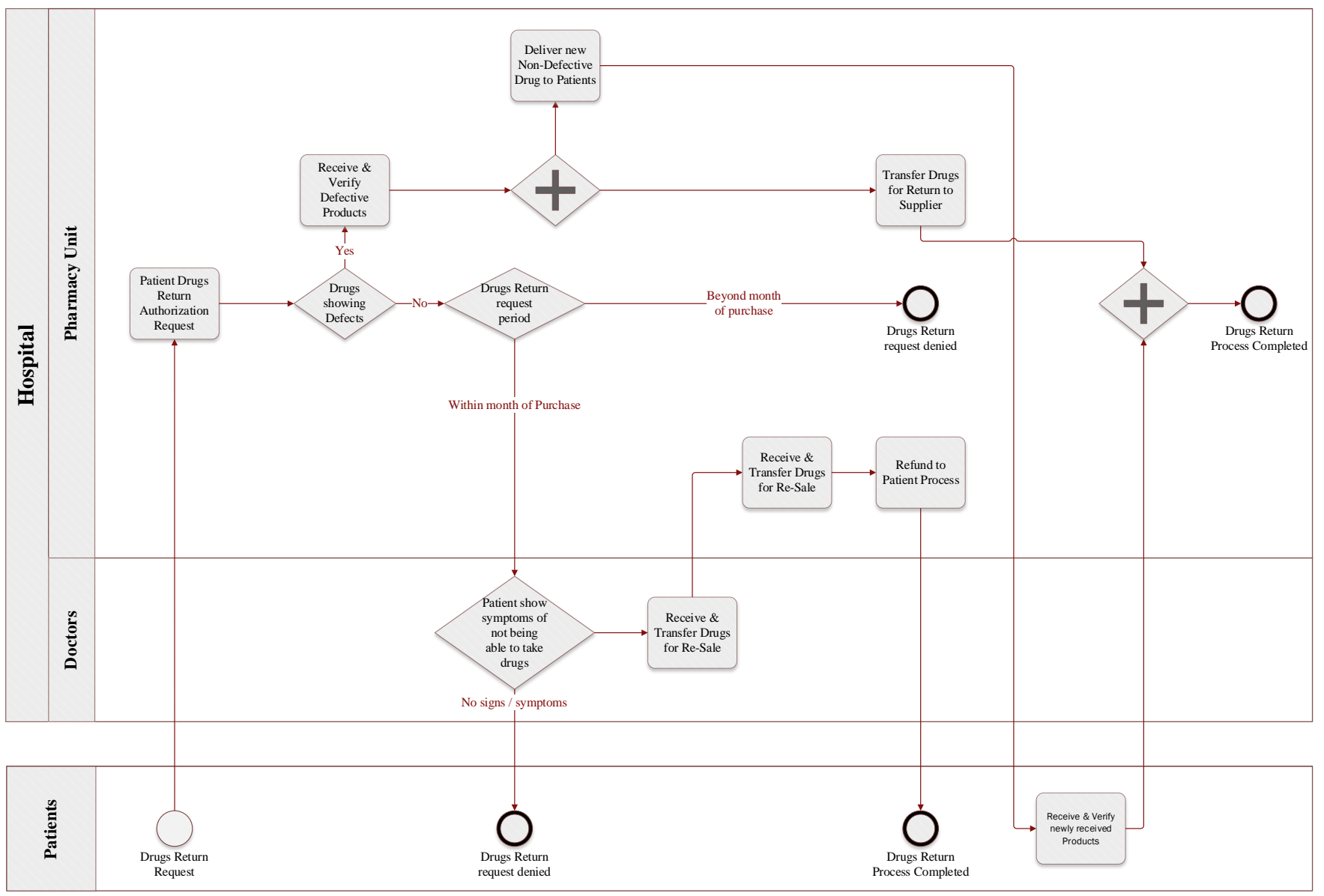

Figure 12 The Return from Patient BPMN model

The next process describes the return of defective or excess product from the Pharmacy to the supplier. This has mostly been covered in the SCOR model and therefore, the BPMN model will add the after-return process in which the hospital receives new products.

The Process for both defective product return \& excess product return is the same other than the fact that the starting event is different. The defective product return is started when a defective product is identified. This may occur during the initial receival of drugs, or it may also happen during the drug storage. As the previous BPMN model shows, this return process also caters to the defective product return found by the Patients after customer purchase.

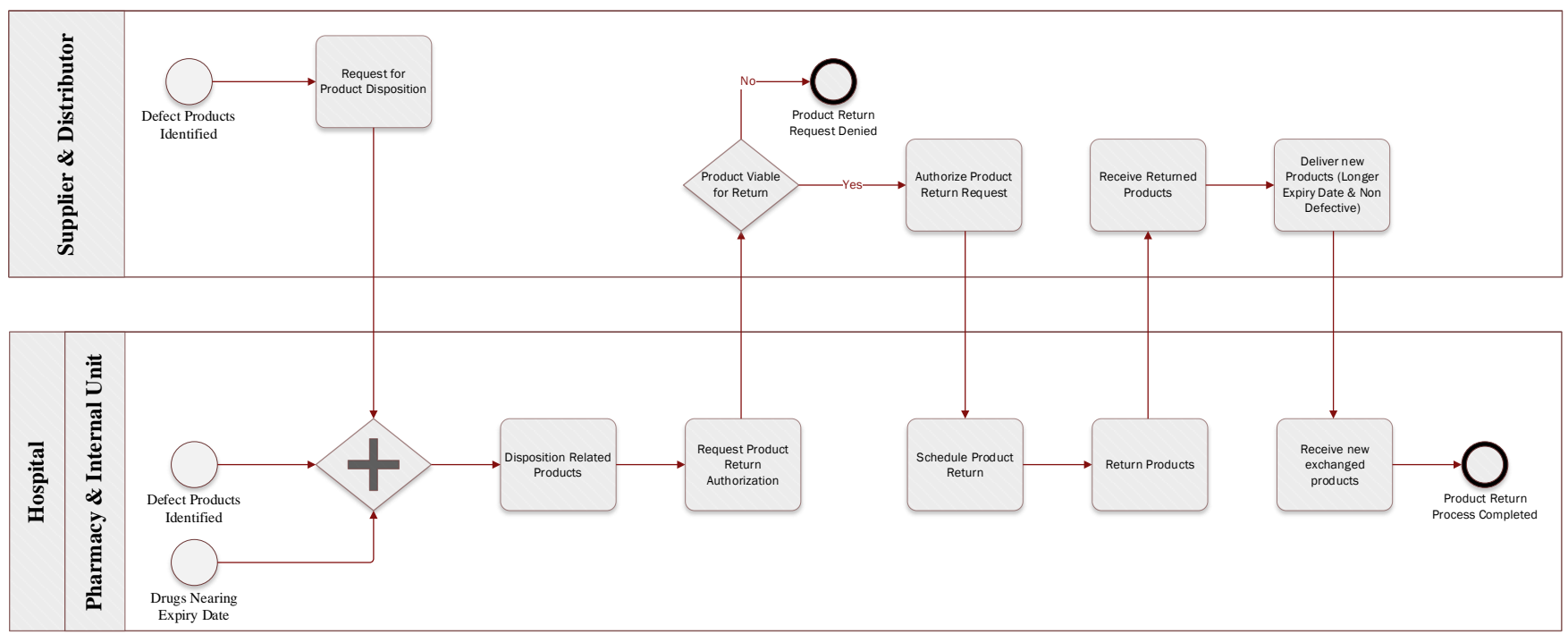

Figure 13 The Return to Supplier BPMN model 
When the defective product is identified, the return process continues by dispositioning said drugs and then submitting the approval request for drugs return to the supplier. The same goes for the Defect Product return requested by the Supplier, at such case, the Supplier will request the defective product batch to be dispositioned. For the excess product return, the process is usually done on certain periods, specifically when the drugs are nearing its expiry date, usually around 3-6 months before the expiry date. After the initial return product identification and disposition, the Supplier will then assess the conditions of the drugs to be returned. This include checking the packaging condition, as well as the storage condition for the

\section{CONCLUSION}

The research done in this thesis is aimed to better understand the Supply Chain Management in the Hospital, specifically regarding the Supply Chain Business Processes. The Supply Chain Processes identified to be researched in this Thesis was Sourcing or Purchasing, Delivery or Distribution, as well as Return activities including Receiving Return products and Returning products. The research also aims to create a SCOR model for the Hospital Supply Chain Operation so as to assist in the Supply Chain Process Analysis. In this thesis, the Researcher has succeeded in creating the model for all 3 level of SCOR, as well as the additional BPMN model for the identified processes.

In the first level of SCOR, often dubbed the strategic level of the Supply Chain, the research shows the process Return Drugs from Patients which is not a common practice in Pharmacy Supply Chain Operation. Although the condition for such return is very specific, the research shows that the process does exist, alongside the usual Pharmacy Return to Supplier which is more common.

The Second level modelling further details each process categories existing in the Hospital. The modelling confirms how there are no Make Process or even any Supply Flow concerning anything other than Stocked Products. All transactions are conducted via a Principal Supplier who will then appoint a Distributor to deal directly with the Hospital regarding transactions \& deliveries. In the Return Process, the Research confirms there are 2 types of Sourcing Product Return, as opposed to Mezouar (2016) research which shows only return of defective products. The additional Return Process involves returning Excess Product or unsold products which are nearing its expiry date. In this instance, the Hospital will return said products and receive new products with longer expiry date. Additionally, the Level 2 SCOR model research also identifies Hospital Internal Users whom acts as a Customer, in addition to the Patients

The third level of SCOR details each Process Categories previously existing in the Level 2 SCOR. However, even in this level, the research identified variance in each process category. Specifically, in the Deliver Process due to the result of the Interview which confirmed the existence of Hospital Internal Users as well as the less common return of Defective products. Once the drugs are deemed viable for return, the process continues with the scheduling for the product return. Once the schedule is confirmed by both the Pharmacy and the Supplier, the Supplier will pick up the returned drugs, usually during their next visit on the Sourcing process. After the drugs has been returned, the supplier will then deliver the new products to replace the returned products. The given drugs, as in the sourcing process will always be at least have one year of expiry life. The Pharmacy will then receive the products and once verifying \& confirming it to be in good condition, the process is completed. Figure 13 shows the BPMN model for the Process.

Telemedicine Patients. In summation, the Processes modelled in the Level 3 SCOR model are the Source Stocked Product (sS1), Deliver Stocked Product for Conventional Patients, Telemedicine Patients, and Hospital Internal Users (sD1), Source Return Defective Product (sSR1), Source Return Excess Product (sSR3), and the Deliver Return Defective Product (sDR1).

The BPMN model serves to detail some processes not able to be detailed by the SCOR model. There are 4 distinct BPMN model created in this Thesis, the Sourcing or Purchasing Process, the Delivery Process, the Return from Patients Process, and Return to Supplier Process. In the Sourcing Process, the added process is the Starting Event in which a drug purchase may be initiated by either the Hospital Pharmacy as periodic purchase, Low-stock purchase, or Users inquiry. In the Delivery Process, no specific process is added other than the detailing of each Process Element in the SCOR model. In the Return from Patients, due to the very specific conditions in which patients are allowed to return Drugs, the model mostly details the Authorization for Return process. In the Return to Supplier Model, the added process is the Return Process inquired by the Supplier rather than the Hospital Pharmacy.

From the result obtained in this research, some Managerial implications able to be concluded from this thesis research are:

1. The use of BPMN in complement to SCOR shows a modelling scheme able to detail some non-standardized but important processes needed to be done in a Hospital Pharmacy Supply Chain

2. The modelling of Pharmacy Supply Chain Operation done using BPMN \& SCOR will assist hospital managements to identify crucial points or redundant points in their Supply Chain Process.

3. The modelling done using BPMN shows some processes which are not listed \& covered by SCOR standard, thereby giving some input to Supply Chain Council (SCC) for the next iteration of the SCOR model. 
In addition to the managerial implications listed above, some recommendations for future research includes:

1. Analysis of Hospitals Supply Chain Process for operations risk management

2. Analysis of Hospitals Supply Chain Process for lean operations improvement

3. Analysis of Hospitals Supply Chain Process Performance using SCOR Performance Metrics in the previously modelled SCOR.

\section{AUTHORS' CONTRIBUTIONS}

Both Authors contributed in the Research Analysis Design, Data Analysis, and Writing of Paper. Author 1 solely contributes in Data Collection.

\section{ACKNOWLEDGMENTS}

The Author would like to express Gratitude to all parties involved in the completion of this research \& the writing of this paper.

\section{REFERENCES}

[1] Deloitte, Hospital Profit Margins \& New Revenue Streams, https://www2.deloitte.com/us/en/pages/lifesciences-and-health-care/articles/improve-hospitalprofit-margins.html, 2017.

[2] Triulzi I., Public Hospital Supply Chain: Current View and Critical Issues in Italy, Value in Health, Volume 20, Issue 9, 2017, pp. 515 - 516. DOI: 10.1016/j.jval.2017.08.660

[3] Bhakoo, V., Singh, P., Collaborative management of inventory in Australian hospital supply chains: practices and issues, Supply Chain Management: An International Journal Vol. 17/2, 2012, pp. 217-230. DOI: https://doi.org/10.1108/13598541211212933

[4] Kusnandar, V.B., 63 Persen Rumah Sakit di Indonesia Dimiliki Swasta, https://databoks.katadata.co.id/datapublish/2019/10/11/ 63-persen-rumah-sakit-di-indonesia-dimiliki-swasta, 2019.

[5] Goodbaum, B., Streamlining the Hospital Supply Chain: Just What the Doctor Ordered, https://www.inboundlogistics.com/cms/article/streamli ning-the-hospital-supply-chain-just-what-the-doctorordered, 2015.

[6] Nyaga, G. N., Young, G. J., \& Zepeda, E. D., An analysis of the effects of intra- and interorganizational arrangements on hospital supply chain efficiency, Journal of Business Logistics, Vol. 36, 2015, pp. 340354. DOI: $10.1111 /$ jbl.12109

[7] Rotaru, K., Wilkin, C. and Ceglowski, A., Analysis of SCOR's approach to supply chain risk management, International Journal of Operations \& Production Management, Vol. 34 No. 10, 2014, pp. 1246-1268. DOI: 10.1108/IJOPM-09-2012-0385
[8] John, N.E., \& Saviur, O.S., \& Essien, U.A., Supply Chain Management Practices and Hospital Operational Efficiency: The Nigerian Example, International Journal of Scientific and Research Publications, Volume 9, Issue 7, 2019. DOI: 10.29322/IJSRP.9.07.2019.p9180

[9] Huijsman, R., \& Vissers, J. M. H., Supply chain management in health care: state of the art and potential, The emerging world of chains and networks: bridging theory and practice, 2004, pp. 147-167.

[10] Al-Sa'ada, R.J., Supply Chain Management and Its Effect on Health Care Service Quality: Quantitative Evidence from Jordanian Private Hospitals, Journal of Management and Strategy Vol. 4, No. 2, 2013. DOI: https://doi.org/10.5430/jms.v4n2p42

[11] Supply Chain Council, Supply Chain Operating Reference Model Revision 11.0, Supply Chain Council, Inc. SCOR: The Supply Chain Reference ISBN 0-615-20259-4, 2011.

[12] Dumas, Marlon. La Rosa, Marcello. Mendling, Jan. Reijers, Hajo A., Fundamentals of Business Process Management, Springer Heidelberg New York Dordrecht London, 2013.

[13] Buttigieg, S.C., \& Dey, P.K., \& Gaucy, D., Business process management in health care: current challenges and future prospects, Innovation and Entrepreneurship in Health, Vol. 3, 2016, pp. 1-13. DOI: https://doi.org/10.2147/IEH.S68183

[14] Persson, F., SCOR template: A simulation based dynamic supply chain analysis tool, International Journal of Production Economics, Vol. 131, 2011, pp.288-294.

DOI: https://doi.org/10.1016/j.ijpe.2010.09.029

[15] Mezouar, H.A. El Afia, R., Ouzayd, F., Proposal of a modeling approach and a set of KPI to the drug supply chain within the hospital, 2016 3rd International Conference on Logistics Operations Management (GOL), Fez, 2016, pp. 1-6. DOI: 10.1109/GOL.2016.7731691

[16] Kasi, V., Systemic Assessment of SCOR for Modellign Supply Chains, Proceedings of the 38th Hawaii International Conference on System Sciences, 2005. DOI: $10.1109 /$ HICSS.2005.574

[17] Lhassan, E., Ali, R., Majda, F., Combining SCOR and BPMN to support supply chain decision-making of the pharmaceutical wholesaler distributors, 2018 4th International Conference on Logistics Operations Management (GOL), 2018. DOI: 10.1109/GOL.2018.8378078

[18] Cheng, Jack C.P., Law, K.H., Bjornsson, H., Jones, A., Sriram, R.D., Modelling and Monitoring of Construction Supply Chains, Advanced Engineering Informatics, Vol. 24, 2010, pp. 435-455. DOI: https://doi.org/10.1016/j.aei.2010.06.009 